\title{
12 Dicas sobre a importância do sono para estudantes de Medicina
}

\section{Geraldo Lorenzi Filho}

1. Cerca de um terço dos alunos da FMUSP tem sonolência excessiva diurna.

2. A principal causa de sonolência entre os aluno é a privação de sono.

3. As fases do sono de ondas lentas e a fase REM (movimento rápido dos olhos) são fundamentais para a fixação de memória.

4. O sono é fundamental para metabolização de radicais livres.

5. A privação de sono esta associada à obesidade.

6. A privação de sono esta associada à depressão.

7. A privação de sono esta associada a aumento de risco cardiovascular.

8. Em 1900 dormíamos cerca de 9hs, hoje dormimos em media menos do que 7 hs.

9. O número de horas que precisamos dormir é variável, mas em média somos uma sociedade privada de sono.

10.Se você dorme no final de semana muito mais do que durante a semana, você provavelmente esta privado de sono.

11. Dormir não é perda de tempo.

12.A privação de sono só tem um remédio: Dormir.

Tutor, fazendo parte do Programa Tutores FMUSP desde 2001. Pneumologista, diretor do Laboratório do Sono (InCor), é tutor porque gosta do contato com os alunos. Escolheu ser médico porque sempre sonhou em ajudar as pessoas. Quando estudante não sabia direito o que seria o seu futuro e hoje, na sua especialidade, diz que seu cotidiano é "fantástico, sempre um desafio". Gosta de conversar em seu grupo de tutoria sobre assuntos diversos, mas deseja orientar os alunos especialmente em dois assuntos: Iniciação Cientifica e Estágios no exterior.

Endereço para correspondência: Geraldo Lorenzi Filho. Av. Dr. Enéas de Carvalho Aguiar, 44 - Cerqueira César, São Paulo, SP. CEP: 05403-000. e-mail: geraldo.Iorenzi@incor.usp.br 